\title{
Testing and long-term monitoring of a curved concrete box girder bridge
}

\author{
Hugo C. Gomez ${ }^{\mathrm{a}, *}$, Paul J. Fanning ${ }^{\mathrm{b}, 1}$, Maria Q. Feng ${ }^{\mathrm{a}, 2}$, Sungchil Lee ${ }^{\mathrm{a}}$ \\ ${ }^{a}$ Department of Civil E Environmental Engineering, University of California-Irvine, Irvine, CA 92697-2175, USA \\ ${ }^{\mathrm{b}}$ School of Architecture Landscape E' Civil Engineering, Newstead Building, Belfield, University College Dublin, Ireland
}

\section{A R T I C L E I N F O}

\section{Article history:}

Received 18 August 2010

Received in revised form

16 February 2011

Accepted 25 May 2011

Available online 7 July 2011

\section{Keywords:}

Bridge

Test vehicle

Natural frequencies

Long-term monitoring

System identification

Ambient vibration

Curved concrete box girder

\begin{abstract}
A B S T R A C T
Capital investment in national infrastructure is significant. The need to maintain and protect critical infrastructure links has led in recent years to significant developments in the area of structural health monitoring. The objective is to track a structure's long-term performance, typically using sensors, and to successively compare the most recently measured responses with prior response history. During construction of the West Street On-Ramp, a curved concrete box girder bridge, located in the city of Anaheim (California), eleven accelerometers were permanently installed on its bridge deck. The associated data acquisition system was configured to record once a specified threshold acceleration response was exceeded; during the period 2002-2010 a total of 1350 datasets including six earthquakes, for each of the eleven sensors, were acquired. This automatically acquired data was supplemented, during the summer of 2009, with responses measured during controlled vehicle tests. Six accelerometers were additionally installed on the frame of the weighed test vehicle. This paper presents the findings of the analyses of these measured data sets and serves to inform owners and managers as to the potential feedback from their instrumentation investment. All response histories were analyzed using frequency domain techniques for system identification. Extraction of the modal characteristics revealed a continuous reduction, of approximately $5 \%$, in the first three natural frequencies over the period of the study. The measured responses from the vehicle sensors are discussed in the context of identifying the potential for bridge frequency measurement using instrumented vehicles.
\end{abstract}

(C) 2011 Elsevier Ltd. All rights reserved.

\section{Introduction}

Long-term continuous monitoring programs are increasingly used to track structural integrity and to identify at what time, if any, structural intervention might be required. The timely undertaking of combined preventative and essential maintenance strategies results in reduced total life cycle costs [1]. Additionally, Orcesi et al. [2] argue that coupling traditional life-cycle management techniques with structural health monitoring will enable even more accurate identification of optimum maintenance strategies for a range of limit states. Long-term continuous or intermittent monitoring provides the best method for understanding and quantifying the actual loading environment and corresponding bridge responses [3].

Long-term monitoring programs serve different objectives and take different forms. Refs. [4-6] are review papers which define the

\footnotetext{
* Corresponding author. Tel.: +1 9493004079.

E-mail addresses: gomezh@uci.edu (H.C. Gomez), paul.fanning@ucd.ie (P.J. Fanning), mfeng@uci.edu (M.Q. Feng), sungcl@uci.edu (S. Lee).

1 Tel.: +353 $17167777 \times 3220$.

2 Present address: The Henry Samueli School of Engineering, University of California-Irvine, Irvine, CA 92697-2175, USA. Tel.: +1949 3788666.
}

ultimate goal of structural health monitoring as damage detection. A significant body of literature discusses shifts in natural frequencies and attempts to link these to various structural deterioration mechanisms. Specifically in the area of bridges Choi et al. [7] and Guan et al. [8] discuss the variation in natural frequencies detected from vibration data measured during a 2-year period. Soyoz and Feng [9] reported a 5\% decrease in the frequency of the first mode of vibration for a bridge over a 5-year monitoring period. Salawu [10] and Farrar et al. [11] discuss the variability of modal parameters due to environmental effects such as changes in temperature, humidity, amount of traffic, etc. and other researchers have studied the deterioration of bridge decks with special emphasis on the contribution of reinforcement corrosion [12-16].

In long-term monitoring practice, bridge vibration response time-histories are extensively used to extract modal parameters, i.e. natural frequencies, modal shapes and damping ratios. The advent of output only system identification algorithms has enabled modal parameters to be extracted from ambient responses without knowledge of the excitation force [17]. Both time domain and frequency domain output-only system identification algorithms are available; frequency domain algorithms are more popular due to their simplicity [18]. The frequency domain decomposition (FDD) technique [19] has since been widely used for system identification of bridges [9,20-23]. 


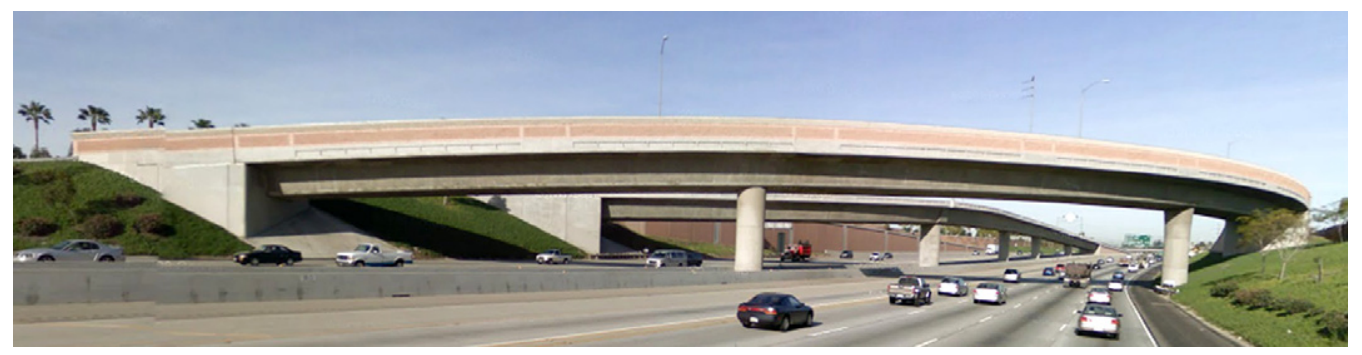

Fig. 1. The west street on-ramp (WSOR) bridge.

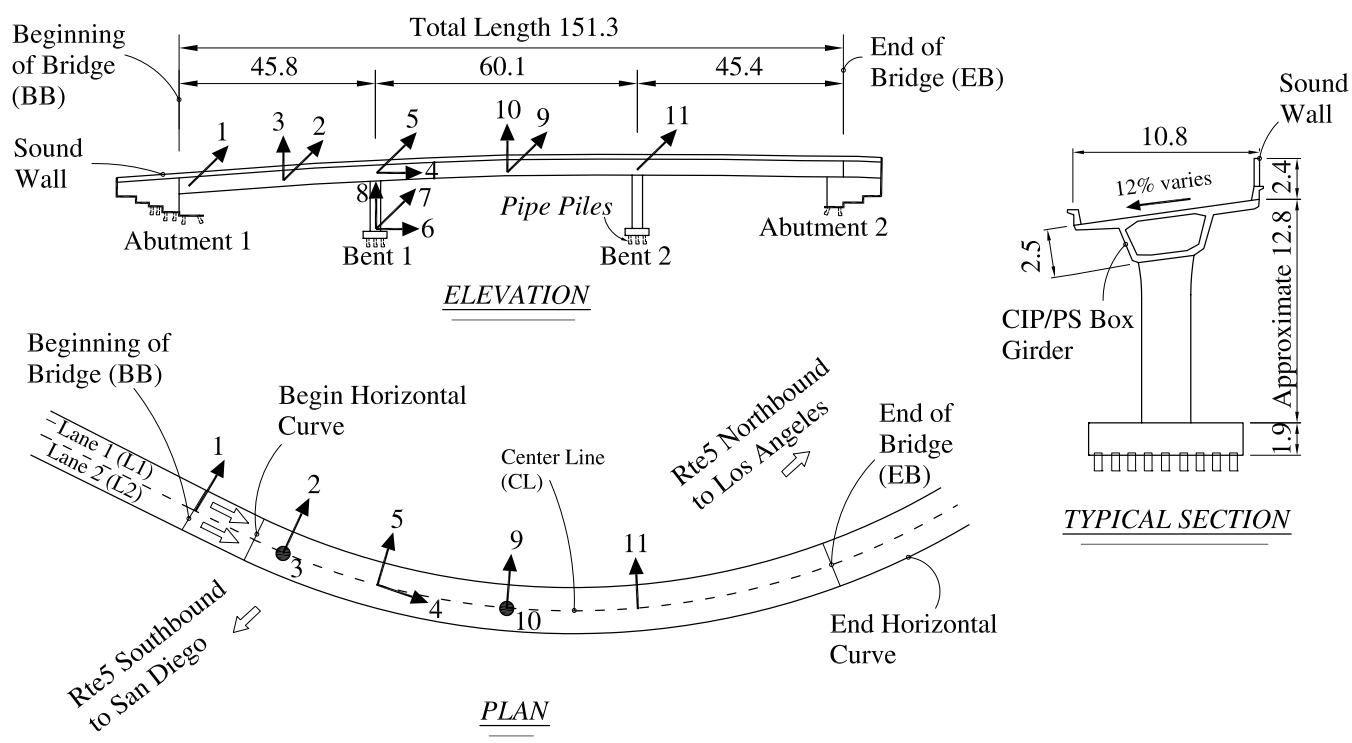

Fig. 2. The west street on-ramp structural details and instrumentation layout. The arrows indicate the orientation of the 11 channels. Dimensions in $m$.

Researchers have also attempted the identification of bridge frequencies from instrumented vehicles. Yang et al. [24] showed that bridge frequencies can be extracted from the vehicle acceleration spectrum. Lin and Yang [25] identified bridge frequencies using an accelerometer mounted on a trailer that was pulled by a light truck although they found that the possibility of identifying bridge frequencies is lost as the crossing speed increases due to instability of the lightweight trailer.

In this paper 8 years of monitored data from the West Street On Ramp (WSOR), a curved post-tensioned reinforced concrete box girder bridge in California, are analyzed using the FDD technique for system identification. The responses due to controlled vehicle tests, from summer 2009, are also discussed. There were three motivating factors for the vehicle tests; firstly to explain the preferential excitation of certain modes of vibration during the long-term monitoring, secondly to examine the potential for determining the modal properties of the bridge using sensors mounted on the test vehicle and thirdly to look at the effect of speed and traveling lane on the dynamic response of the bridge.

There are two primary objectives of the paper; (i) to demonstrate the practical use of monitored data for long-term structural condition assessment and (ii) to examine the potential of vehicle mounted sensors in determining bridge frequencies in the absence of sensors mounted on a bridge. To accomplish the first objective the proposed approach is based on the tracking of both frequency and mode shape variation so as to distinguish between system changes due to gradual aging or due to a significant occurrence of damage. To achieve the second objective system identification is applied to data acquired from sensors mounted on the vehicle chassis.

\section{West Street On-Ramp (WSOR) bridge}

The West Street On-Ramp (WSOR), Fig. 1, is a three span continuous curved concrete box girder bridge spanning $151.3 \mathrm{~m}$ (496.5 ft) over the Santa Ana Freeway (I-5) in the city of Anaheim, California.

Summary plan and section details are provided in Fig. 2. The box girder is a single-cell cast-in-place pre-stressed and post-tensioned concrete box girder aligned at $12 \%$ to the horizontal. Concrete traffic barriers, integral with the deck, $0.8 \mathrm{~m}$ high, are provided on outer edges of both traffic lanes with an additional $1.6 \mathrm{~m}$ high sound wall on the south side. In plan the radius of curvature is $167.6 \mathrm{~m}$ and the three spans, running south to north, are $45.8 \mathrm{~m}$, $60.1 \mathrm{~m}$ and $45.4 \mathrm{~m}$ long respectively. At opposite abutments the box girder is supported on two reinforced elastomeric bearing pads in abutment seats and is nominally simply supported. The bents, $2.7 \mathrm{~m}$ diameter, are continuous with the box girder due to the main bent reinforcement being anchored in solid concrete diaphragms filling the girder void at these locations. Each bent is founded on a reinforced concrete pad footing supported in turn on sixty nine $0.4 \mathrm{~m}$ diameter, approximately $10 \mathrm{~m}$ long tubular steel piles.

The WSOR Bridge was designed in accordance with the American Association of State Highway and Transportation Officials (AASHTO) "1983 Standard Specifications for Highway Bridges with interims and revisions by Caltrans" [26]. Once construction was completed in 2001 the WSOR became the first permanently instrumented curved short-span bridge in Orange County, California.

\section{Long-term monitoring and vehicle crossing tests}

Data monitoring commenced in 2002. The various accelerometer locations on the bridges are indicated in Fig. 2. Accelerometer 

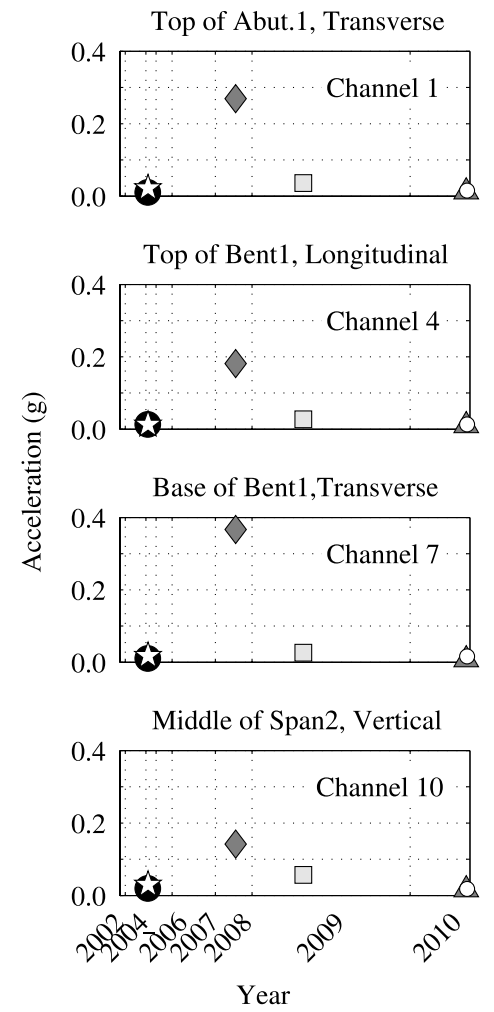

Middle of Span1, Transverse

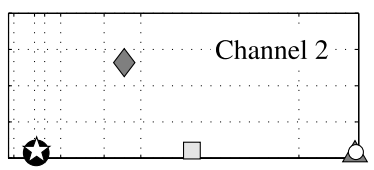

Top of Bent1,Transverse

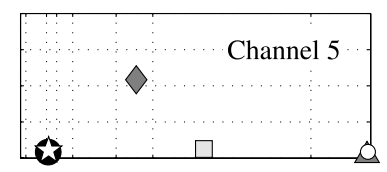

Base of Bent1,Vertical

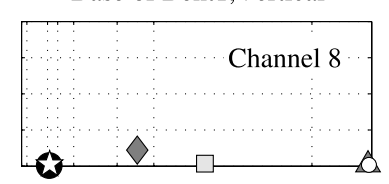

Top of Bent2, Transverse

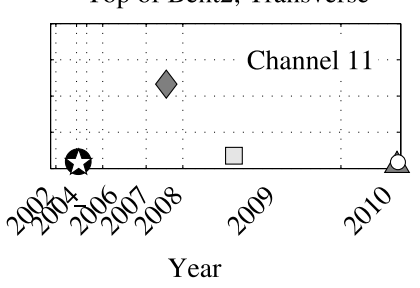

Middle of Span1, Vertical

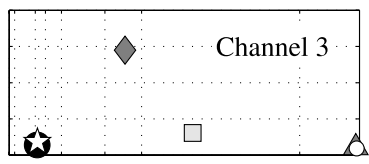

Base of Bent1,Longitudinal

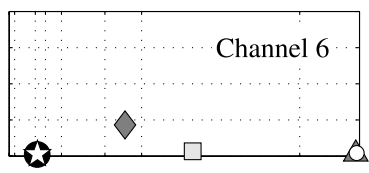

Middle of Span2, Transverse

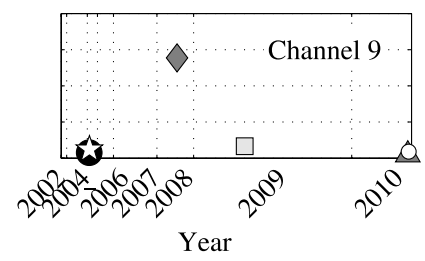

2005 Anza, Mw=5.2, Epicentre $=129 \mathrm{~km}$ 2005 Yucaipa, $\mathrm{Mw}=4.9$, Epicentre $=88 \mathrm{~km}$ 2008 ChinoHills, $\mathrm{Mw}=5.4$, Epicentre $=21 \mathrm{~km}$ 2009 Inglewood, $\mathrm{Mw}=4.7$, Epicentre $=41 \mathrm{~km}$ 2010 PicoRivera, $\mathrm{Mw}=4.4$, Epicentre $=24 \mathrm{~km}$ 2010 Calexico, $\mathrm{Mw}=7.2$, Epicentre $=300 \mathrm{~km}$

Fig. 3. Peak accelerations due to seismic excitation.

orientations facilitated the capture of 6 transverse (\#'s 1, 2, 5, 7, 9, 11), 3 vertical (\#'s 3, 8, 10), and 2 longitudinal (\#'s 4, 6) measurement data sets simultaneously.

The monitoring system was configured to record automatically at acceleration levels exceeding $0.002 \mathrm{~g}$ in either channels 6,7 or 8 at the base of Bent 1 . Once triggered data is sampled at $100 \mathrm{~Hz}$ for $60 \mathrm{~s}$ corresponding to a Nyquist frequency of $50 \mathrm{~Hz}$, which has previously been shown to be sufficient to accurately capture the lower modes of vibration of bridges of this category [22]. In the period to April 2010, 1350 datasets were recorded. A manual triggering option was used during vehicle crossing tests in order to continuously record the bridge response to the multiple crossings of the test vehicle.

The test vehicle used was a Caltrans water truck, weighed at a local weigh-station prior to tests, with a gross vehicle weight of $225 \mathrm{kN}$ (mass of 22,980 kg) made up from $57 \mathrm{kN}$ at the front axle and $84 \mathrm{kN}$ on each of the two rear axles.

\subsection{Acceleration responses}

\subsubsection{Automatically triggered records}

By correlating recording dates with seismic activity in the state of California it was possible to separate the data into responses due to seismic excitation and responses due to other excitation sources. These other excitation sources are predominantly crossing traffic or adjacent traffic. The peak accelerations recorded on each channel, for seismic and non-seismic excitation, are plotted in Figs. 3 and 4 respectively.

During the monitoring period the maximum peak accelerations were due to seismic activity with the magnitudes of response being a function of the earthquake magnitude and proximity of the earthquake epicenter to the bridge site. For the Chino Hills earthquake, with a magnitude of 5.4 and an epicenter approximately $21 \mathrm{~km}$ (13 mi) from the bridge, peak acceleration responses of the order of $0.3-0.4 g$ were recorded (Fig. 3 ). The peak levels of excitation due to traffic excitation (Fig. 4) are almost an order of magnitude smaller (up to $0.045 \mathrm{~g}$ ). While the Chino Hills earthquake is characterized by large global transverse excitation consistent with a land mass movement comprising the whole bridge the relative vertical acceleration between the base (channel 8 ) and the center of the first span (channel 3 ) is of the order of $0.25 \mathrm{~g}$. This compares to relative vertical accelerations (Fig. 4) of up to $0.045 \mathrm{~g}$, between the same two channels, for traffic induced excitation. The extent of transverse response for the other more remote and smaller magnitude earthquakes is not so pronounced; the peak accelerations and vertical responses at the centers of spans (channels 3 and 10), are at least of similar magnitude to the maximum responses due to traffic excitation.

Comparing the various acceleration levels induced by traffic activity the predominant trigger is the transverse acceleration at the bent base (recorded on channel 7). The peak accelerations along the span direction are more moderate (channel 6) while there is little or no excitation in the vertical direction (channel 8 ). Relative to all other channels these are the locations where least excitation occurs-this is consistent with the abutments being soundly anchored on pile foundations at the bent footings. The dominant response at bridge deck level occurs at the centers of the first (channel 3) and second (channel 10) spans in the vertical directions with maximum peak accelerations (up to $0.045 \mathrm{~g}$ ) occurring in the first span. Transverse accelerations of up to $0.02 \mathrm{~g}$ are also recorded. The variation in acceleration levels recorded on all channels is attributed to varying vehicle (traffic) mass, vehicle velocity and whether or not triggering is due to traffic events on the bridge itself or traffic events on Route 5 passing under the bridge. For example, a larger acceleration response at the center of span 1 would be expected if triggering of the monitoring system was due to a vehicle crossing the bridge than would be observed if the monitoring system was triggered due to traffic effects arising out of activity on Route 5 when the bridge itself might be free of all traffic. 

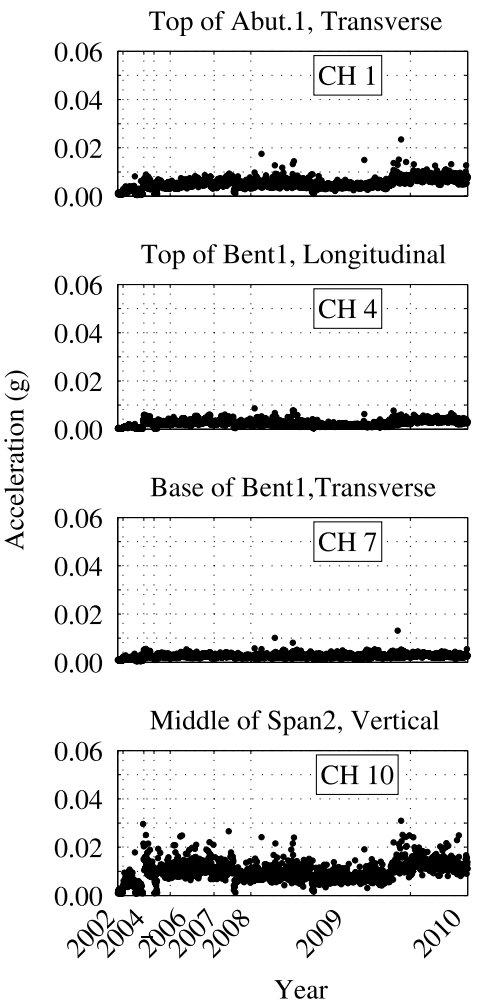

Middle of Span1, Transverse

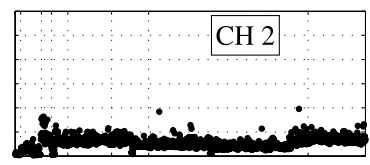

Top of Bent1,Transverse

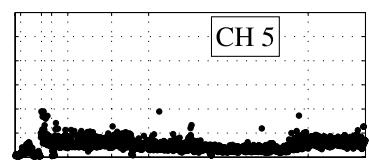

Base of Bent1, Vertical

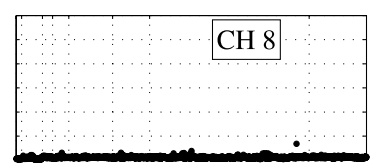

Top of Bent2, Transverse

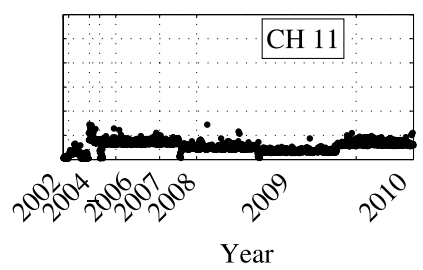

Middle of Span1, Vertical

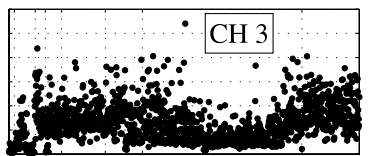

Base of Bent1,Longitudinal

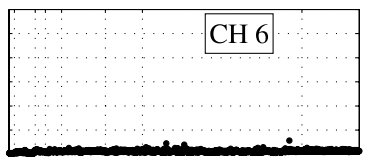

Middle of Span2, Transverse

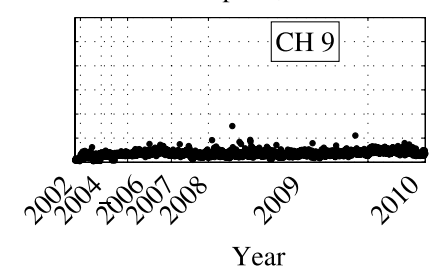

Fig. 4. Peak accelerations due to excitation other than seismic excitation.

Table 1

\begin{tabular}{|c|c|c|c|c|c|}
\hline Test no. & $\begin{array}{l}\text { Speed } \\
\mathrm{m} / \mathrm{s}(\mathrm{km} / \mathrm{h})\end{array}$ & Lane of Trip & Direction & Load type & $\begin{array}{l}\text { Bump/brake } \\
\text { location }\end{array}$ \\
\hline 1 & $4.5(16)$ & $\mathrm{C}$ & BB-EB & ML & \\
\hline 2 & $6.7(24)$ & C & BB-EB & ML & \\
\hline 3 & $6.7(24)$ & $\mathrm{C}$ & BB-EB & ML & \\
\hline 4 & $6.7(24)$ & $\mathrm{C}$ & BB-EB & ML & \\
\hline 5 & $6.7(24)$ & L1 & BB-EB & ML & \\
\hline 6 & $6.7(24)$ & L1 & BB-EB & ML & \\
\hline 7 & $11.2(40)$ & L1 & EB-BB & ML & \\
\hline 8 & $11.2(40)$ & L1 & EB-BB & ML & \\
\hline 9 & $4.5(16)$ & $\mathrm{L} 2$ & BB-EB & ML & \\
\hline 10 & $4.5(16)$ & $\mathrm{L} 2$ & BB-EB & ML & \\
\hline 11 & $8.9(32)$ & $\mathrm{L} 2$ & EB-BB & ML & \\
\hline 12 & $11.2(40)$ & $\mathrm{L} 2$ & EB-BB & ML & \\
\hline 13 & $11.2(40)$ & $\mathrm{C}$ & EB-BB & BRL & S2 \\
\hline 14 & $11.2(40)$ & $\mathrm{C}$ & EB-BB & BRL & $\mathrm{S} 2$ \\
\hline 15 & $6.7(24)$ & L1 & BB-EB & BPL & S2 \\
\hline 16 & $6.7(24)$ & L1 & BB-EB & BPL & S3 \\
\hline 17 & $11.2(40)$ & $\mathrm{L} 2$ & EB-BB & BPL & S3 \\
\hline 18 & $11.2(40)$ & $\mathrm{L} 2$ & EB-BB & BPL & S3 \\
\hline 19 & $4.5(16)$ & $\mathrm{C}$ & BB-EB & BPL & S2, S3 \\
\hline 20 & $6.7(24)$ & $C$ & EB-BB & BPL & S2, S3 \\
\hline 21 & $11.2(40)$ & $\mathrm{L} 2$ & EB-BB & BPL & $\mathrm{S} 2, \mathrm{~S} 3$ \\
\hline 22 & $11.2(40)$ & $\mathrm{L} 2$ & EB-BB & BPL & S2, S3 \\
\hline
\end{tabular}

\subsubsection{Vehicle crossing tests}

The sequence and descriptors for the various vehicle crossing tests are listed in Table 1 . All vehicle crossing tests were undertaken in a single day of closure of the bridge to all other traffic. Relative to the beginning of the bridge (BB), see Fig. 2, both forward (BB-EB) and return (EB-BB) crossings were undertaken with the vehicle using either traffic lane, L1 (northside) or L2, and also traveling along the center line of the bridge $(\mathrm{CL})$. The range of tests studied the effects of a normal moving load (ML), the presence of a timber 'bump' obstruction (BPL) and a sudden 'braking' load (BRL). For the 'bump' tests a timber joist (approximately $0.05 \times$
$0.05 \mathrm{~m}$ in cross section) was laid on the road surface, for the test vehicle to travel over, close to the centers of spans 1-3 (locations S1, S2 and S3). For 'braking' tests the driver was instructed to brake suddenly (at locations S1, S2 or S3) until a complete stop was reached and then re-start. In each test the driver was instructed to maintain a steady vehicle speed. Unfortunately, high speeds were not attainable due to available run-off distances at either end of the bridge. Therefore, vehicle speeds ranged between 'very slow' (approximately $4.5 \mathrm{~m} / \mathrm{s}, 16 \mathrm{~km} / \mathrm{h})$, 'slow' $(6.7-7.6 \mathrm{~m} / \mathrm{s}$, 24-27 km/h), 'medium' $(8.9 \mathrm{~m} / \mathrm{s}, 32 \mathrm{~km} / \mathrm{h}$ ) to 'moderate' (up to $11.2 \mathrm{~m} / \mathrm{s}, 40 \mathrm{~km} / \mathrm{h}$ ). The quoted speeds are those reported by the 

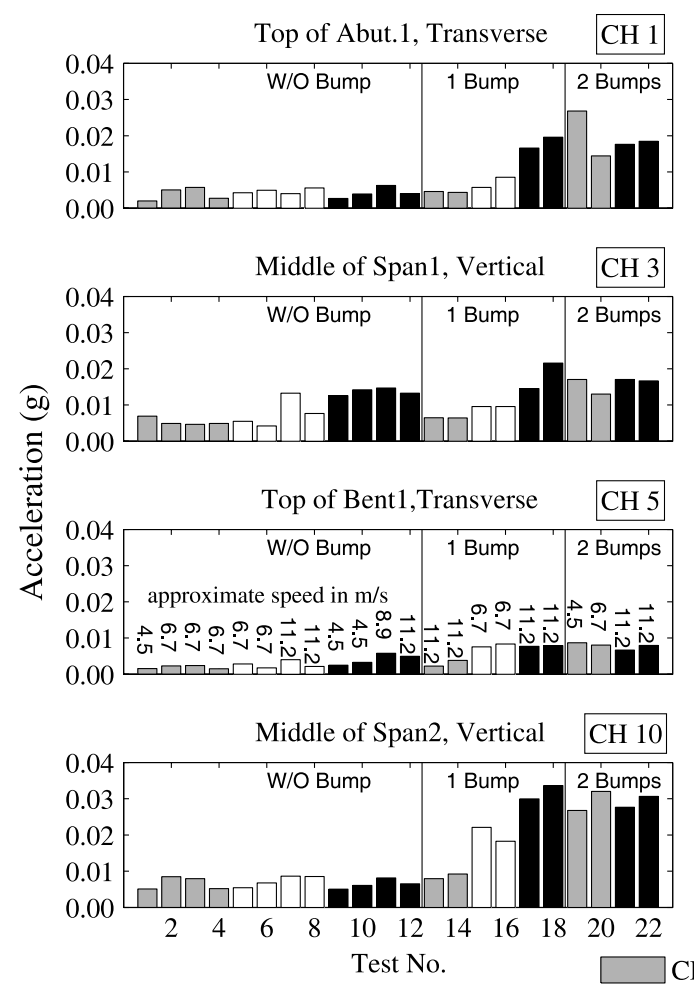
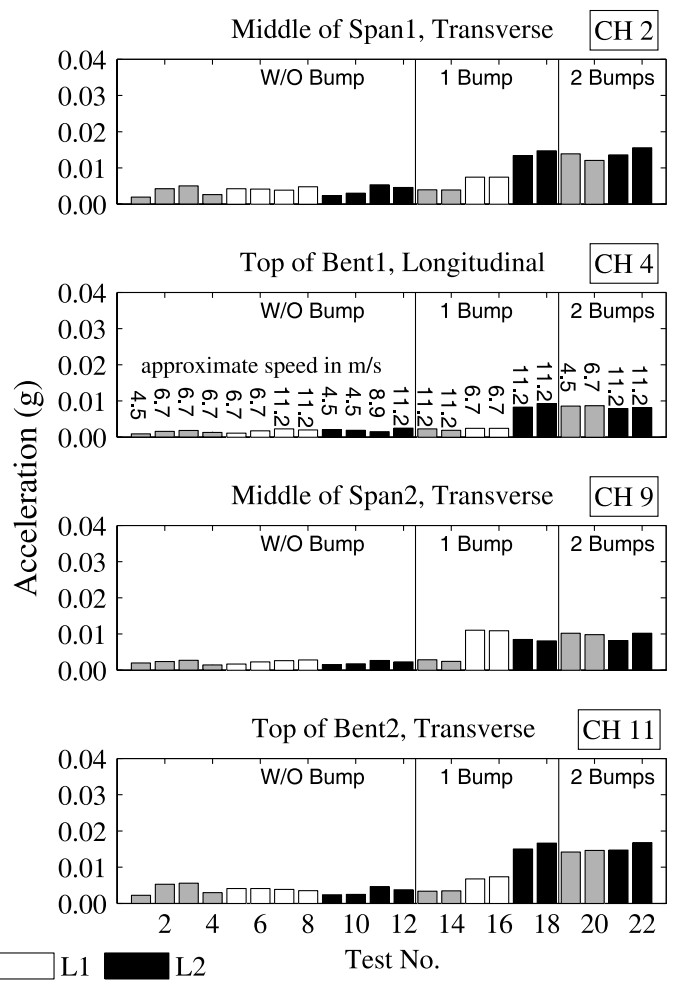

Fig. 5. Peak accelerations for vehicle crossing tests.

driver at the end of each test, however, it should be noted that these predetermined and constant crossing speeds were difficult to specify and control accurately.

The peak acceleration readings recorded during each of the tests are plotted in Fig. 5. For the range of tests and vehicle speeds considered, there is no discernible relationship between the crossing speed and magnitude of response. In tests $5 \& 6$ the vehicle traversed the bridge from EB to BB at a 'slow' speed while the speed was increased to 'moderate' for tests $7 \& 8$ without any significant difference in recorded response.

In the absence of bumps on the roadway the maximum vertical acceleration recorded in the middle of the first and second spans were approximately $0.015 \mathrm{~g}$ and $0.010 \mathrm{~g}$ respectively. Compared to the responses in these spans during the long-term monitoring program this suggests that the bulk of the vehicles, or combinations of vehicles, triggering the monitoring system, and for which data is retained, are of at least similar weight to the test vehicle with peak masses (based on peak responses on these channels of $0.045 \mathrm{~g}$ and $0.025 g$ respectively) in the order of three times the test vehicle weight.

During the vehicle crossing tests the maximum responses occurred when there were bumps on the road surface. In test 12 the test vehicle traveled along the bridge from the end of the bridge (EB-BB) at $11.2 \mathrm{~m} / \mathrm{s}$ (40 km/h, $25 \mathrm{mph}$ ) resulting in an acceleration response of less than $0.01 \mathrm{~g}$ at the center of span 2 (channel 10). On repeating this test with a bump in span 3 (the first span traversed as the test vehicle travels from the end of the bridge back to the beginning) the acceleration response increases to $0.035 \mathrm{~g}$ (tests 17 \& 18)- more than a threefold increase in response attributable to the bump. This is due to an increased dynamic load imparted by the vehicle having been excited by the bump.

The single bump tests (tests 13-18), during which speeds were approximately $6.7 \mathrm{~m} / \mathrm{s}(24 \mathrm{~km} / \mathrm{h}, 15 \mathrm{mph})$ on lane L1 and $11.2 \mathrm{~m} / \mathrm{s}$ ( $40 \mathrm{~km} / \mathrm{h}, 25 \mathrm{mph}$ ) on lane $\mathrm{L} 2$ and on the center CL, indicate that the induced excitation of the vehicle by the bump is more significant than any speed effect. The L1 test responses are consistently higher than the CL tests despite the lower test speeds. For these tests the critical parameter was the lane in which the vehicle traveled with the highest responses recorded for L2 tests followed by L1 and then CL tests. This is attributed to lanes L1 and L2 being offset from the centroidal axis of the bridge deck and hence the mobilization of a torsional response in the deck system. At the middle of span 2 (channel 10) the bridge response is amplified by up to $300 \%$ when the test vehicle travels in L2 compared to along the centerline. The same effect is not apparent in the tests without bumps indicating that it is induced external excitation of a crossing vehicle rather than its crossing speed that is the most important parameter for bridge vehicle interaction studies.

\subsection{Identification of modal parameters}

The dynamic properties of the WSOR were determined using the frequency domain decomposition (FDD) technique [19] for all datasets. In order to reduce background noise a butterworth infinite impulse response filter of order 8 was applied to the data with a passband defined by a lower frequency of $1 \mathrm{~Hz}$ and a higher frequency of $10 \mathrm{~Hz}$.

\subsubsection{Ambient vibration records}

The first singular values extracted from two datasets measured on 01/06/2010 are plotted in Fig. 6. The third natural frequency is consistently identified at $2.64 \mathrm{~Hz}$, while the first and second are identified as being between $1.86-1.90 \mathrm{~Hz}$ and $2.30-2.34 \mathrm{~Hz}$ respectively. The respective amplitudes for the different modes vary between the two datasets. For the data recorded at 10:57 am the three modes are equally prominent whereas in the later dataset (11:43 am) the contributions of the first and third modes are not as prominent. The vehicle crossing tests, discussed later, explain the cause of this variation in the identified modal parameters.

Partial mode shapes (as only two spans of the three were instrumented), associated with these frequencies, are plotted in Fig. 7, along with full 3D numerical modes determined 


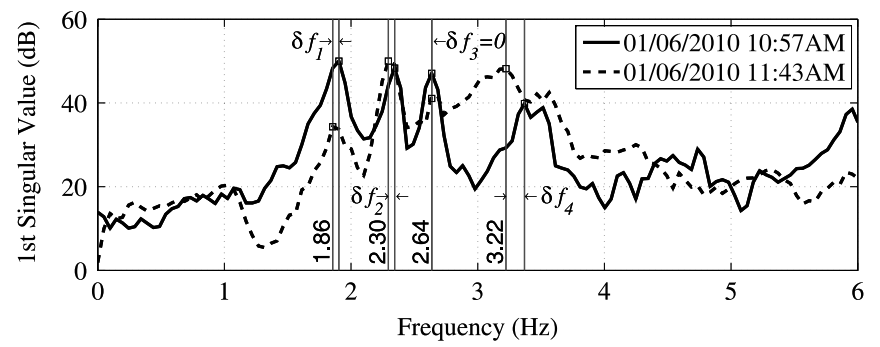

Fig. 6. Frequency domain decomposition applied to two data sets measured on $01 / 06 / 2010$ at $10: 57 \mathrm{am}$ and $11: 43$ am respectively.

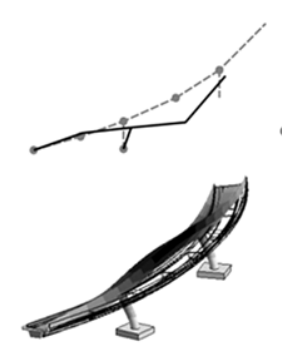

Mode 1
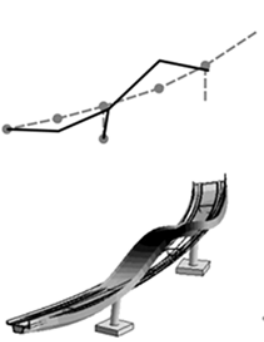

Mode 2
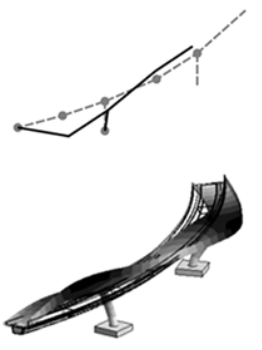

Mode 3

Fig. 7. Measured and numerical modes of vibration.

separately [27]. These numerical modes are needed to complete the missing information at the third span. Although the first three modes exhibit some vertical and horizontal coupling it is clear that the first mode is a lateral rocking mode about the longitudinal axis of the bridge with both bents in phase. The second mode of vibration is the first vertical bending mode of the bridge deck while the third identified mode of vibration is a mode combining rocking, with the bents out of phase with each other, and transverse bending of the bridge deck.

The first three frequencies identified from singular value plots, constructed for all ambient vibration records are plotted in Fig. 8. Over the course of the monitoring period from 2002-2010 the frequencies were found to occur within three different bands.

For the data recorded during 'Winter 2002' the frequencies are clustered around 2.0, 2.4 and $2.84 \mathrm{~Hz}$. The slight variation in
Table 2

Variation in the WSOR average identified natural frequencies from 2002 to 2010.

\begin{tabular}{lllllll}
\hline \multicolumn{7}{l}{ Average identified natural frequencies } \\
\hline Year & $\begin{array}{l}\mathrm{f} 1 \\
(\mathrm{~Hz})\end{array}$ & $\begin{array}{l}\text { Increment } \\
(\%)\end{array}$ & $\begin{array}{l}\mathrm{f} 2 \\
(\mathrm{~Hz})\end{array}$ & $\begin{array}{l}\text { Increment } \\
(\%)\end{array}$ & $\begin{array}{l}\mathrm{f} 3 \\
(\mathrm{~Hz})\end{array}$ & $\begin{array}{l}\text { Increment } \\
(\%)\end{array}$ \\
\hline 2002 & 2.04 & - & 2.45 & - & 2.83 & - \\
2004 & 1.96 & -4.03 & 2.41 & -1.69 & 2.76 & -2.74 \\
2005 & 1.95 & -0.17 & 2.40 & -0.64 & 2.77 & 0.58 \\
2006 & 1.92 & -1.77 & 2.38 & -0.65 & 2.72 & -2.06 \\
2007 & 1.91 & -0.31 & 2.36 & -0.86 & 2.70 & -0.65 \\
2008 & 1.90 & -0.71 & 2.35 & -0.36 & 2.69 & -0.21 \\
2009 & 1.86 & -2.01 & 2.33 & -1.11 & 2.66 & -1.23 \\
2010 & 1.88 & 1.29 & 2.33 & 0.10 & 2.68 & 0.66 \\
\hline
\end{tabular}

individual frequencies during 'Winter 2002', and other identified timeframes, can be attributed to the specific conditions that pertained during each triggered event-for example different traversing vehicle masses, or indeed no vehicle mass on the bridge if triggering was caused due to traffic passing on Route 5 beneath the bridge.

For all datasets subsequent to 'Winter 2002' the banded distribution of frequencies is similar although there is a small, but consistently gradual, reduction in the frequency of vibration for all modes. The average annual frequencies, along with percentage incremental changes, are listed in Table 2. During the 8 year monitoring period the reduction in frequency for the first and third modes is of the order of $8 \%$ and $7 \%$ respectively compared to a more modest $5 \%$ for the second mode.

Using the modal assurance criterion (MAC) [28] identical mode shapes yield a MAC value of unity while truly orthogonal mode shapes result in a MAC value of zero. The variation in the resulting MAC matrix terms over the duration of the monitoring period are plotted in Fig. 9. The modes are substantially consistent (MAC values of unity for diagonal terms) and orthogonal (MAC values of zero for off-diagonal terms).

\subsubsection{Vehicle crossing tests}

First singular values from the data recorded during vehicle crossing Test 1 and Test 21, are plotted in Fig. 10(a). The first and second frequencies, identified at $1.86 \mathrm{~Hz}$ and $2.25 \mathrm{~Hz}$, are consistent with those obtained due to automatic triggering of the

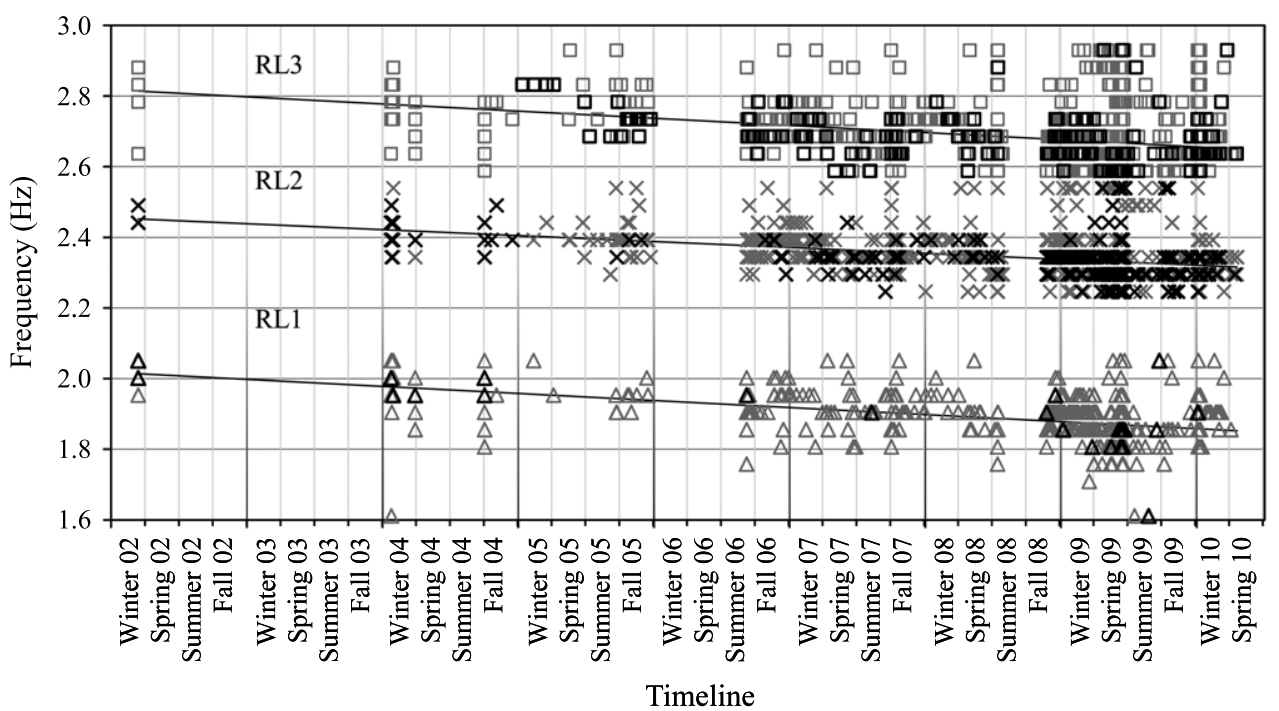

RL1: $f{ }_{1}=-0.0198$ (\# of years)+2.0137; RL2: $f{ }_{2}=-0.0168$ (\# of years) $+2.452 ; \quad$ RL3: $f^{*}{ }_{3}=-0.0202$ (\# of years) +2.8137

\begin{tabular}{|lll|}
\hline$\Delta$ mode 1 & $\times$ mode 2 & $\square$ mode 3 \\
$\Delta$ mode 1 - most prominent & $\times$ mode 2 - most prominent & $\square$ mode 3 - most prominent \\
\hline
\end{tabular}

Fig. 8. WSOR identified frequencies from 2002 to 2010. 


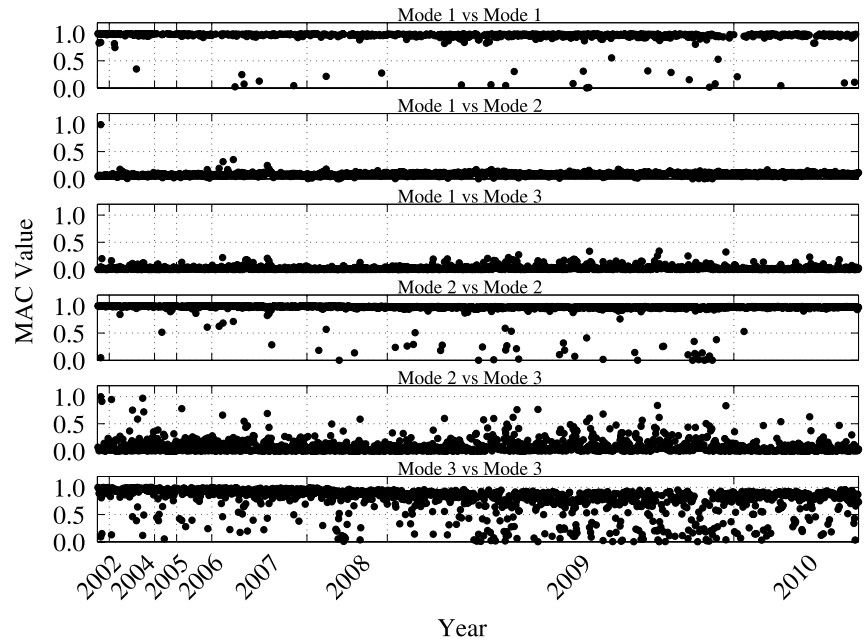

Fig. 9. Variation in MAC values from 2002 to 2010.

monitoring system indicating that the mass of this particular vehicle on the bridge does not significantly affect its frequencies. However, the first dominant mode excited is the first bending mode of the bridge (the second mode of vibration) at approximately $2.25 \mathrm{~Hz}$. The higher modes excited close to $3 \mathrm{~Hz}$ and above are higher bending modes. The aforementioned predominant excitation of the bending mode of the bridge (Fig. 7), the second mode of vibration, is consistent with the passage of a vehicle over the bridge which would be expected to preferentially excite the first bending mode (the second mode of vibration of the bridge in this case).

Time histories recorded using sensors mounted on the vehicle chassis were also post-processed to obtain frequency domain data. The first singular value for vehicle crossing Test 5 (see Table 1) is plotted in Fig. 10(b). While there are multiple frequency peaks identified, which include the previously identified bridge frequencies, the dominant frequencies of response are 2.93 and $6.055 \mathrm{~Hz}$.

Test vehicle axle loads and sensor locations on the vehicle chassis are shown in Fig. 11(a) and (b) respectively. Vibration modes of the water truck, generated using the six transducers (T1-T6) mounted on the chassis, are shown in Fig. 11(c)-(g). Mode shapes at the vehicle dominant frequencies of response, $2.93 \mathrm{~Hz}$ and $6.055 \mathrm{~Hz}$, identify these two prominent peaks as being associated with the dynamics of the test vehicle, see Fig. 11(c) and
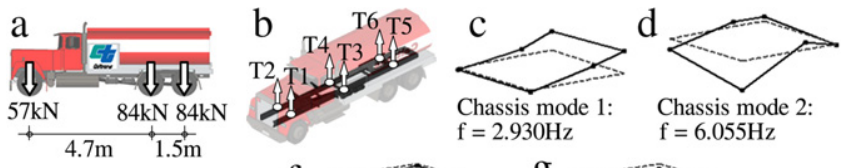

Chassis mode 1: Chassis mode 2: $\mathrm{f}=2.930 \mathrm{~Hz} \quad \mathrm{f}=6.055 \mathrm{~Hz}$

e
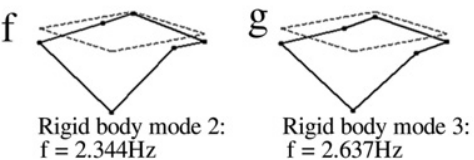

Rigid body mode 1: $\mathrm{f}=1.904 \mathrm{~Hz}$

$\mathrm{f}=2.344 \mathrm{H}$

$\mathrm{f}=2.637 \mathrm{~Hz}$

Fig. 11. Test vehicle vibration modes identified from test 5 : (a) axle loads of vehicle; (b) sensor layout on vehicle chassis; (c) and (d) chassis vibration modes; (e)-(g) rigid body vehicle modes.

(d). The mode at $2.93 \mathrm{~Hz}$ is a rocking mode of the vehicle on its suspension system while the mode at $6.035 \mathrm{~Hz}$ is the first chassis bending mode.

Mode shapes constructed, from the vehicle sensor set, at the bridge frequencies of $1.90,2.34$ and $2.637 \mathrm{~Hz}$ are plotted in Fig. 11(e)-(g). If the motion of the first corner sensor (T1) with the maximum amplitude of vibration is discounted, as it was discovered after testing that this sensor was not adequately bonded to the vehicle chassis, the three modes extracted from the vehicle data, at the bridge frequencies are essentially rigid body modes of vibration of the vehicle indicating that at these frequencies the vehicle mass follows the bridge response.

\section{Discussion of results}

The most significant finding in this paper has been the reduction in the frequencies for the three lower modes of vibration of the WSOR. The magnitude of change amounts to $7 \%-8 \%$ for modes one and three and 5\% for mode two over the course of the eight year monitoring period. The decrease is consistent and gradual and there are no step changes which indicate that the reduction is due to damage attributable to any one of the six earthquakes which registered bridge responses. Bridge management records list no structural interventions or additions and the reducing, rather than varying, frequencies discount seasonal environmental conditions which in any event are relatively uniform in Southern California. The MAC values calculated over the period are consistent indicating no changes in the nature of the various modes.

The peak acceleration recorded due to regular traffic activity is approximately $0.045 \mathrm{~g}$ at the center of the first span (Fig. 4). The distributions of peak accelerations occurrences for channels 3 and
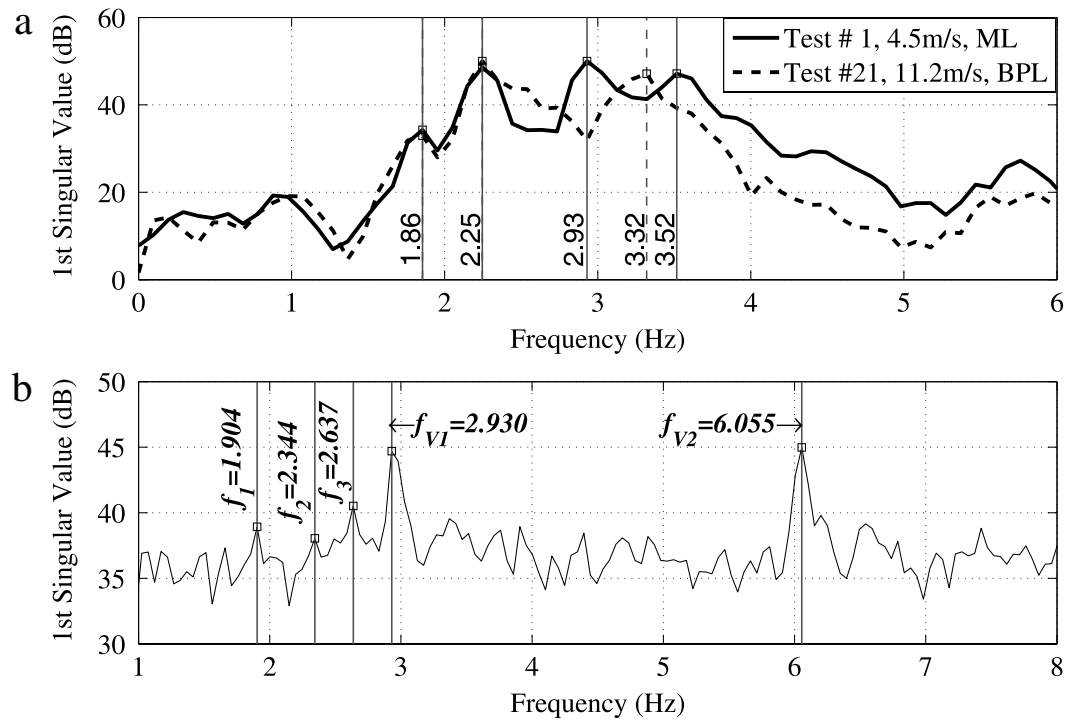

Fig. 10. Frequency domain decomposition applied to data recorded: (a) during vehicles crossing test 1 and test 21 ; (b) on vehicle sensors during test 5 . 

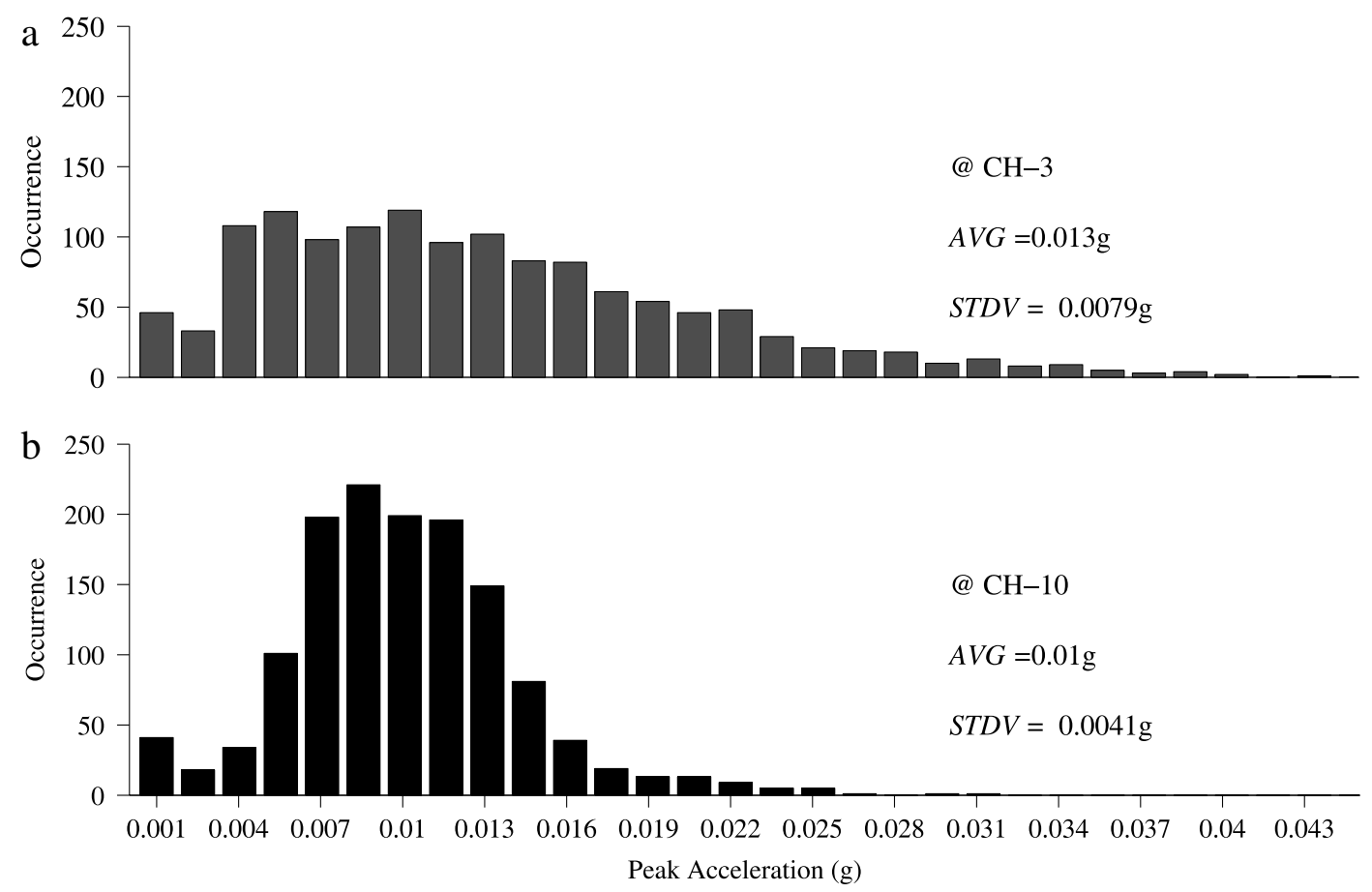

Fig. 12. Occurrence of peak acceleration magnitudes at midspan locations during the monitoring period 2002-2010: (a) CH-3; (b) $\mathrm{CH}-10$.

10, measuring vertical midspan accelerations, Fig. 12, shows that this magnitude of acceleration is attained on a few occasions and that the predominant response is of the order of $0.007-0.015 \mathrm{~g}$. The control vehicle used for the vehicle crossing tests had a total weight of $225 \mathrm{kN}$ (mass of 22,980 kg) and resulted in a peak first span acceleration of approximately $0.015 \mathrm{~g}$. It could thus be sensibly argued that the site specific traffic loading, on this bridge to date, consisted of relatively light vehicles $(<225 \mathrm{kN})$ with occasional, up to 250 over an eight year period, heavier vehicles, or combinations of vehicles, up to a maximum of approximately $675 \mathrm{kN}$ (on very limited occasions) based on the assumption of a direct correlation between vehicle mass and bridge induced acceleration. While this determination is reasonably simplistic it indicates a consistent bridge response due to an expected distribution of vehicle weights.

It is also interesting to note the apparent step change in the acceleration responses at the start of 2005, Fig. 4 . A thesis for this change, supported by the vehicle crossing tests discussed above, is that datasets recorded prior to 2005 are due to excitation by light traffic or passing traffic on Route 5, over which the WSOR spans, while from 2005 onwards it is due to an increased number of heavy vehicles using the bridge. In Fig. 8 the most prominent frequency identified by frequency domain decomposition from any given dataset is identified by a solid marker. Prior to 2005 the first mode of vibration is consistently the most prominent mode; this would naturally be the mode of vibration in the event of excitation from adjacent traffic. From 2005 onwards the second mode dominates in the recorded responses. The singular value frequency domain decomposition plot shown in Fig. 10(a) shows that it is heavy vehicles crossing the bridge that cause the second mode of vibration, the vertical bending mode in Fig. 7 , to be prominent. This implies that those datasets where the second mode is more prominent, over the 2002-2010 monitoring period, are due to heavy vehicles crossing the bridge. These occurrences are rare prior to 2005 but more frequent subsequently. Furthermore, the monitoring system is biased towards maximum acceleration responses as existing data, if not downloaded, is overwritten when the average acceleration is greater than the smallest average acceleration for currently stored datasets and thus when the frequency of heavy vehicles increases the datasets associated with these events dominate the system memory.

The bridge carries traffic in one direction only and it is interesting to note that the response recorded at the center of the first span was consistently higher than that recorded at the center of the second span, channels 3 and 10 in Fig. 4. This is attributed to the positive slope of the bridge over its first span (approximately 5\%) and hence two components of force being applied (vertical and longitudinal) to the bridge causing the vehicle to decelerate as it travels along the first span and also the probability that drivers would have a natural disposition to accelerating as they approach an incline. Once the relatively level second span is reached any vehicle would be traveling at a lower speed and also only one (vertical) component of the load would be applied to the bridge deck.

The relationship between vehicle speed and amplitude of bridge response was not possible to discern from the controlled vehicle crossing tests undertaken. The limited amount of runon space at the beginning of the bridge limited the attainable velocity from a standing start up the first span incline. In terms of vehicle-bridge interaction the most important contributing effect was not vehicle speed but rather whether or not the test vehicle itself was oscillating. In the 'bump' tests the amplification of bridge response was significant, as much as $300 \%$ on some channels. This has clear implications for bridge management strategies. Features that will contribute to vehicle oscillations include the quality of the road profile, discrete damage on the road surface, expansion joints at opposite ends of the bridge and obstructions (or debris) in the traffic lanes. Proper maintenance and timely repair of these features will minimize vehicle oscillation and hence structural demand on the bridge.

The instrumentation mounted on the test vehicle shows some potential, but also some challenges, for the identification of bridge frequencies from vehicle response data alone. In singular value plots derived from vehicle data, Fig. 10(b), the dominant modes identified are, as anticipated, those associated with the test vehicle. While the bridge frequencies are also identifiable they are not prominent and it is arguable whether they could, in the absence of prior knowledge, be confidently identified as frequencies associated with the bridge as opposed to other contributing factors, 
such as undulations in the road profile, which would also appear in the frequency domain plots as peaks.

\section{Conclusions}

Acceleration time-histories measured at eleven channels and gathered over an eight year period, immediately after construction was completed, for the West Street On-Ramp Bridge in Southern California have been analyzed. The findings presented are based on the analysis of 1350 ambient vibration datasets, six earthquake responses and twenty two vehicle crossing tests. Sensors mounted on the test vehicle were also used to assess the potential for measuring bridge frequencies.

Conclusions, specific to the WSOR, derived from this work are:

(1) the second mode of vibration, the first vertical bending mode, is the most dominant mode shape due to vehicle activity on the bridge,

(2) the reduction in frequencies of the WSOR (in the order of $7 \%-8 \%$ for the first and third modes and $5 \%$ for the second mode) has been essentially linear during the 8 years of monitoring,

(3) the gradual and continuous nature of the reduction indicates that it is not due to any of the six earthquake events which registered responses at the bridge site,

(4) the shapes of the modes of vibration are consistent over the monitoring period indicating that the change in frequencies is due to gradual aging processes rather than any discrete damage event(s),

(5) amplification of bridge response due to an obstacle, such as a bump, exceeds any velocity effect,

(6) the response of the WSOR is significantly amplified when a vehicle travels in the lane next to the outer face of the curvature, up to $300 \%$ compared to along the centerline,

(7) bridge frequencies, known a priori, are identifiable from truck sensor data,

while more generally the following conclusions are drawn;

(1) for long-term monitoring of bridge structures tracking of both frequency and mode shape changes is required so as to distinguish between system changes due to gradual aging or due to a significant occurrence of damage,

(2) maintaining a good quality even road surface is a significant measure bridge owners and managers can take to reduce amplification of demand on their bridges due to bridge-vehicle interaction as the amplification of response due to an obstacle is likely to exceed any velocity effect,

(3) the response of highly curved bridges is amplified when a vehicle travels in the lane next to the outer face of the curvature, due to the mobilization of a torsional response in the deck system.

(4) bridge frequencies are captured in vehicle response data but it remains debatable as to whether they could be confidently identified as bridge frequencies without prior knowledge.

It is the authors' opinion that the proposal to use vehicle data for bridge frequency identification deserves further attention. Clearly there is an economic benefit in having a mobile bridge monitoring unit and the potential return for a network of bridges is significant.

The more general conclusions provide important advice, and information, to bridge constructors, owners and managers, in respect of the use of monitored data for distinguishing between gradual aging processes and discrete damage events, and also the importance of maintaining a good road surface to alleviate impact forces due to heavy vehicles. In the future, long-term monitoring data recorded at curved bridges will provide further valuable information about whether more of the specific conclusions in this paper can be generalized or they apply only to the WSOR Bridge.

\section{Acknowledgments}

The authors would like to acknowledge with appreciation to the California Department of Transportation, in particular to $\mathrm{Mr}$. LiHong Sheng for the support that made this research possible. The authors are also grateful to Dr Yoshio Fukuda from the University of California, Irvine who was responsible for the installation of the equipment on the truck utilized for this research.

\section{References}

[1] Neves LC, Frangopol DM. Condition, safety and cost profiles for deteriorating structures with emphasis on bridges. Reliab Eng Syst Saf 2005;89(2):185-98.

[2] Orcesi AD, Frangopol DM, Kim S. Optimization of bridge maintenance strategies based on multiple limit states and monitoring. Eng Struct 2010; 32(3):627-40.

[3] Aktan AE, Farhey DN, Helmicki AJ, Brown DL, Hunt VJ, Lee K-L, et al. Structural identification for condition assessment: experimental arts. J Struct Eng 1997; 123(12):1674-84.

[4] Carden EP, Fanning P. Vibration based condition monitoring: a review. Struct Health Monit 2004;3(4):355-77.

[5] Doebling SW, Farrar CR, Prime MB. A summary review of vibration-based damage identification methods. Shock Vib Diag 1998;30(2):91-105.

[6] Sohn H, Farrar CR, Hemez FM, Shunk DD, Stinemates DW, Nadler BR. A review of structural health monitoring literature: 1996-2001. Los Alamos National Laboratory Report no. LA-13976-MS. Los Almos, NewMexico; 2004.

[7] Choi S, Park S, Bolton R, Stubbs N, Sikorsky C. Periodic monitoring of physical property changes in a concrete box-girder bridge. J Sound Vib 2004;278(1-2): 365-81.

[8] Guan H, Karbhari VM, Sikorsky CS. Web-based structural health monitoring of an frp composite bridge. Comput-Aided Civ Infrastruct Eng 2006:21(1):39-56.

[9] Soyoz S, Feng MQ. Long-term monitoring and identification of bridge structural parameters. Comput-Aided Civ Infrastruct Eng 2009;24(2):82-92.

[10] Salawu OS. Detection of structural damage through changes in frequency: a review. Eng Struct 1997;19(9):718-23.

[11] Farrar CR, Doebling SW, Cornwell PJ, Straser EG. Variability of modal parameters measured on the alamosa canyon bridge. Proceedings of the 15th international modal analysis conference, vol. 1. 1997. p. 257-63.

[12] Akgul F, Frangopol DM. Lifetime performance analysis of existing prestressed concrete bridge superstructures. J Struct Eng 2004;130(12):1889-903.

[13] Enright MP, Frangopol DM. Service-life prediction of deteriorating concrete bridges. J Struct Eng 1998;124(3):309-17.

[14] Rafiq MI, Chryssanthopoulos MK, Onoufriou T. Performance updating of concrete bridges using proactive health monitoring methods. Reliab Eng Syst Saf 2004;86(3):247-56.

[15] Stewart MG, Rosowsky DV. Time-dependent reliability of deteriorating reinforced concrete bridge decks. Struct Saf 1998;20(1):91-109.

[16] Chryssanthopoulos MK, Sterritt G. Integration of deterioration modelling and reliability assessment for reinforced concrete bridge structures. In: Proceedings of the 1st ASRANet international colloquium. 2002.

[17] Peeters B, De Roeck G. Stochastic system identification for operational modal analysis: a review. J Dyn Syst Meas Contr 2001;123(4):659-67.

[18] Ghanem R, Shinozuka M. Structural-system identification. I: theory. J Eng Mech 1995;121(2):255-64

[19] Brincker R, Zhang L, Andersen P. Modal identification from ambient response using frequency domain decomposition. In: Wicks AL, DeMichele DJ, editors. Proceedings of the 18th international modal analysis conference, vol. 4062 (1). 2000. p. 625-30

[20] Chen Y, Feng MQ Tan CA. Modeling of traffic excitation for system identification of bridge structures. Comput-Aided Civ Infrastruct Eng 2006; 21(1):57-66

[21] Chen Y, Tan C-A, Feng MQ, Fukuda Y. A video assisted approach for structural health monitoring of highway bridges under normal traffic. In: Tomizuka M, Yun C-B, Giurgiutiu V, editors. Proceedings of SPIE, vol. 6174 (1). 2006. p. 61741V-18.

[22] Feng MQ, Kim DK, Yi J-H, Chen Y. Baseline models for bridge performance monitoring. J Eng Mech 2004;130(5):562-9.

[23] Feng MQ, Kim D-K, Sheng L-H, Fiji LM, Kim YJ. Instrumentation of bridges for long-term performance monitoring. In: Chase SB, Aktan AE, editors. Proceedings of SPIE, vol. 4337 (1). 2001. p. 139-46.

[24] Yang YB, Lin CW, Yau JD. Extracting bridge frequencies from the dynamic response of a passing vehicle. J Sound Vib 2004;272(3-5):471-93.

[25] Lin CW, Yang YB. Use of a passing vehicle to scan the fundamental bridge frequencies: an experimental verification. Eng Struct 2005;27(13):1865-78

[26] California Department of Transportation, Bridge Design Specifications. 1983 AASHTO with Interims and Revisions by Caltrans, Sacramento, California; 1983.

[27] Fanning P, Feng MQ Gomez HC. Complementing long-term health monitoring of bridges using numerical models. In: Frangapol D, Sause R, Kusko C, editors. Proceedings of the 5 th international association for bridge maintenance and safety conference. 2010. p. 2957-62.

[28] Allemang R, Brown D. Juhl PB, editor, A correlation coefficient for modal vector analysis. Proceedings of the 1 st international modal analysis conference, vol. 1 (1). 1982, p. 110-16. 